\title{
Breast Cancer Susceptibility-Towards Individualised Risk Prediction
}

\author{
Inge M. M. Lakeman ${ }^{1} \cdot$ Marjanka K. Schmidt ${ }^{2}$. Christi J. van Asperen ${ }^{3} \cdot$ Peter Devilee $^{1,4}$
}

Published online: 17 May 2019

(C) The Author(s) 2019

\begin{abstract}
Purpose of Review Breast cancer is the most common cancer among females in developed countries. Strategies such as early detection by breast cancer screening can reduce the burden of disease but have disadvantages including overdiagnosis and increased cost. Stratification of women according to the risk of developing breast cancer, based on genetic and lifestyle risk factors, could improve risk-reduction and screening strategies by targeting those most likely to benefit.

Recent Findings Breast cancer risk is partly determined by genetic factors including rare pathogenic variants in susceptibility genes and common low-risk variants. Other risk factors include alcohol use, smoking, reproductive factors, hormonal factors, family history, mammographic density, BMI, and body height. Ideally, all risk factors are combined into an individual breast cancer lifetime risk score, but this requires knowledge about their interactions as well as accurate effect sizes. A few risk models seem to be sufficiently developed to inform clinical risk management to minimise cancer risk of those at increased risk and avoid overtreatment of those at decreased risk.

Summary In this review, we briefly summarise the breast cancer susceptibility factors and discuss avenues towards combining all these factors to create individual risk scores.
\end{abstract}

Keywords Breast cancer $\cdot$ Gene panel $\cdot$ Polygenic risk score $\cdot$ Individualised breast cancer risk prediction

\section{Introduction}

Breast cancer is the most common cancer among women in Europe, with approximately 523,000 cases diagnosed annually [1] and remains a leading cause of death among adult women. Primary prevention of breast cancer by endocrine therapy has side effects and is not absolute, whereas prophylactic surgery is very effective [2] but socially and emotionally burdensome. Secondary prevention by early detection through

This article is part of the Topical Collection on Cancer Genomics

Peter Devilee

p.devilee@lumc.nl

1 Department of Human Genetics, Leiden University Medical Centre, Postal zone S4-P, Albinusdreef 2, 2333ZA Leiden, The Netherlands

2 Department of Molecular Pathology, and Department of Psychosocial Research and Epidemiology, Netherlands Cancer Institute-Antoni van Leeuwenhoek Hospital, Amsterdam, the Netherlands

3 Department of Clinical Genetics, Leiden University Medical Centre, Leiden, the Netherlands

4 Department of Pathology, Leiden University Medical Centre, Leiden, the Netherlands mammographic screening can reduce mortality but at the cost of overdiagnosis and the burden of false-positive results [3, 4]. Stratification of women according to the risk of developing breast cancer could provide a persuasive rationale for surgical intervention as well as improve the efficacy of risk-reduction and screening strategies by tailoring starting age and frequency $[5,6 \cdot]$.

Box 1 Definition of breast cancer risk

Clinically, definitions such as low, moderate, and high breast cancer risk are often used. However, this can reflect relative or absolute risks. For a given relative risk (RR), absolute risk can vary between countries depending on cancer incidences. Another term often used is lifetime risk, which is the absolute risk of breast cancer over the period of a woman's life. Here, we define moderate risk as RR $=2$ to 4 , high risk as $\mathrm{RR}>4$, and low or population risk as $\mathrm{RR}<2$.

To accurately assess a woman's risk, it is important to take all risk factors into account. Having a positive family history is one of the main risk factors for breast cancer. For women with a first-degree relative with breast cancer, the risk for developing breast cancer is twofold compared with women without such a family history [7]. Approximately $25 \%$ of this familial relative risk (FRR) is explained by (likely) pathogenic variants in a small number of genes, and a further $18 \%$ by the currently 
known common low-risk variants, mostly single nucleotide polymorphisms (SNPs) [8, 9, 10•, 11]. Besides the familial relative risk, other risk factors such as mammographic density and lifestyle factors are also important. In this review, we briefly summarise the breast cancer susceptibility factors, and then discuss avenues towards combining all these factors to create individual risk scores, and towards the identification of factors capable of explaining the remainder of familial relative risk.

\section{Rare Genetic Variation Associated with Breast Cancer}

The definition of 'rare' variation is somewhat arbitrary but is generally taken as to occur in $<0.5 \%$ of the general population. Indeed, we currently know that some variants associated with risk to breast cancer are extremely rare $(<0.001 \%)$, others moderately rare $(\sim 0.1 \%)$, or even almost 'common' $(\sim 1 \%)$. In addition, the risks conferred by these variants may vary from less than twofold to over tenfold. Classic linkage analysis in multiple-case families discovered some of the genes, but many were discovered by DNA sequencing of candidate genes. The best-known examples of linkage-detected genes are $B R C A 1$ and $B R C A 2[12,13]$. Pathogenic variants in either gene, each with a joint allele frequency of $\sim 0.1 \%$, will lead to a high risk of breast and ovarian cancer [14, 15]. Other genes, particularly TP53, PTEN, STK11, CDH1, and NF1, were discovered because of their association with typical familial cancer syndromes of which breast cancer is one feature [16-20]. Accordingly, their prevalence in the population is extremely rare. These findings also underscore the pleiotropic effects that some DNA variations display by predisposing to cancers of diverse tissue origin. Yet for most breast cancer genes discovered so far, the most conspicuous 'other' cancer with which an association has been firmly established is ovarian cancer. Another 'syndromic' gene is ATM; pathogenic variants in ATM act in a recessive way to cause Ataxia telangiectasia, a neurodegenerative disorder, but heterozygous carriers are at moderately increased risk for breast cancer [21]. The discovery that $B R C A 1, B R C A 2$, and $A T M$ are involved in DNA damage repair, and that $B R C A 2$ is a Fanconi anaemia gene [22], suggested that other DNA repair genes might also confer breast cancer susceptibility. Sequence analysis of these candidates then led to the discovery of $C H E K 2, B A R D 1$, $P A L B 2, N B N$, and $R A D 51 D$ [23-27] as breast cancer genes, although evidence is sometimes limited to specific variants in populations of specific ethnic background [26]. Breast cancer risks in these five genes are generally moderate, with the exception of loss-of-function variants in $P A L B 2$, which can lead to breast cancer risks comparable to $B R C A 2$ [26, 28].

There is a long list of genes, including BRIP1, FANCC, FANCM, MEN1, MRE11A, PPM1D, RAD50, RAD51B,
$R A D 51 C, R E C Q L$, and $X R C C 2$, for which an association with breast cancer has been reported in a few studies, but for which replication in sufficiently large samples of cases and controls and establishment of effect sizes are still lacking. In fact, $B A R D 1$ and RAD51D were only recently confirmed in such analyses as moderate-risk genes [29•]. Finally, a long-standing issue is whether the Lynch syndrome genes (MLH1, MSH2, MSH6, and PMS2) and MUTYH are associated with breast cancer risk. Interpretation of breast cancer incidence in studies of Lynch syndrome families is complicated due to various biases (e.g., ascertainment). The issue remains controversial to date, even though a recent study again found an association between pathogenic variants in MSH6 and breast cancer risk [30]. More detailed discussions on the association of gene variants and breast cancer and the corresponding risks can be found in reviews by Wendt et al., Easton et al., and Graffeo et al. [26, 27, 31].

Box 2 Classification of gene variants

The ACMG has recommended a five-tier classification system, which has been adopted by many countries [32]. These classes are (1) Benign, (2) Likely Benign, (3) VUS, (4) Likely Pathogenic, (5) Pathogenic. For

VUS, the pathogenicity and hence the association with disease risk are unknown, usually because they result in a similarly shaped amino acid or reside in a part of the gene not essential for its function.

\section{Challenges in Risk Assessment and Clinical Translation}

Once a gene has been repeatedly associated with breast cancer, other challenges arise that may hamper introduction into the clinic. One is allelic diversity and the notion that different types of variants (e.g., nonsense versus missense changes) might confer different breast cancer risks [26]. For BRCA1 and BRCA2, the effect of mutation-position on the relative risks for breast and ovarian cancer has been firmly established [33]. Furthermore, several missense changes have been identified in BRCA1 and BRCA2 that cause much more moderate risks than the typical loss-of-function variants $[34 \bullet, 35]$. Conversely, while most pathogenic variants in ATM will give an intermediate breast cancer risk, one specific missense mutation (c. $7271 \mathrm{C}>\mathrm{G}$ ) seems to reach a level of risk approaching that of $B R C A 1 / 2$ pathogenic variants $[36,37]$. The presence of allelic diversity in breast cancer genes also highlights the difficulties we are still having with establishing pathogenicity for each variant. This seems straightforward for protein-truncating variants (although exceptions exist [38]), but for many missense and 'spliceogenic' variants the impact on protein function (and, by inference, on cancer risk) is hard to predict. The many in silico tools available for this purpose still perform poorly with respect to clinical standards, and for virtually all genes 
listed above, well-calibrated high-throughput functional analyses in model systems are lacking [39]. As a result, many variants detected by sequencing in these genes are still classified as Variants of Uncertain Significance (VUS).

Another challenge is to establish the penetrance of pathogenic variants and the corresponding breast cancer risks with sufficient accuracy. With some exceptions, there is still much uncertainty surrounding the magnitude and precision of the risks conferred by pathogenic variants in the genes. One problem underlying this issue is ascertainment bias in the sample used in the analyses. Patient series consisting mostly of women with a positive family history are almost certainly overestimating risk due to the enrichment of other risk factors. This is especially true for tumour syndrome genes, investigation of which is usually triggered by the syndrome criteria. For example, the penetrance of TP53 variants was initially estimated to be very high [40]. But with the introduction of gene panel sequencing, pathogenic variants in TP53 were also reported in families who do not fulfil the classical criteria of LiFraumeni Syndrome [41]. These families show older ages of onset of breast cancer [42], suggesting lower penetrance of at least some TP53 pathogenic variants. This is consistent with recent estimates of the prevalence of pathogenic germline TP53 variants in the general population [43], which are also much higher than expected on the basis of the prevalence of Li-Fraumeni Syndrome alone. The other problem is the rarity of variants, which necessitates the analysis of very large casecontrol series in order to sufficiently narrow down confidence intervals of risk estimates. For this reason, we have reasonably good breast cancer risk estimates for the $1100 \mathrm{delC}$ variant in CHEK2, which occurs in $\sim 0.5 \%$ of the general population in Europe [44, 45] and the USA [29•, 45], but not for most other, much rarer variation in this gene. To establish an odds ratio of 2 with a $95 \%$ confidence interval of $1.4-2.8$, conferred by a variant with an allele frequency of $0.01 \%$, it would require genotyping 100,000 cases and 100,000 controls. Larger numbers are needed for lower risks and lower allele frequencies.

\section{Gene Panel Studies-Non-BRCA1/2 Genes}

Gene panel sequencing (GPS) has become a diagnostic reality in cancer genetics. Due to the lower costs and improving data quality, it became possible to test multiple genes in addition to $B R C A 1$ and BRCA2 in a single assay, driven by a desire to explain familial clustering of breast cancer in more families and thus impact clinical management. As explained above, the frequency of pathogenic variants found in clinic-based series of familial cases is dependent on the selection criteria of the families included. The highest frequencies, up to $10 \%$, of pathogenic variants are still found in the BRCA1 and BRCA2 genes in familial breast cancer cases [46-48]. Pathogenic variants in non-BRCA1/2 genes are found in $3.7-6.2 \%$ of the cases [29•, 46-50]. The highest frequencies of pathogenic variants in non-BRCA1/2 genes are found in CHEK2, ATM and PALB2 [29•]. However, this increased diagnostic yield comes at the expense of a large proportion of detected VUS, which poses a significant clinical problem. Gene panel studies have found a VUS in 13.6-41.6\% of the cases [46, 48, 49, 51]. This means that for every pathogenic variant found in a case, two to three cases with VUS are detected. Furthermore, gene panels contain many genes for which the relevance to breast cancer is unknown or uncertain, as outlined above. Due to these uncertainties, most of the test results of commercial gene panels do not translate well into cancer risk assessment. Even the relatively well-defined cancer risks conferred by $B R C A 1$ and $B R C A 2$ are influenced by mutation position and mutation class, as well as by non-genetic exposures and lifestyle factors $[35,52,53]$. Therefore, the gain in clinical utility of testing genes for which evidence of their association with breast cancer is still ill-defined remains limited [26, 54].

\section{SNPs and Polygenic Risk Scores}

Since 2005, genome-wide association studies, using SNP arrays and very large case-control samples, enabled the identification of common low-risk variants for breast cancer [11]. Collaborative groups, such as the Breast Cancer Association Consortium (BCAC), have currently identified $~ 180$ SNPs as significantly associated with breast cancer [10॰]. The first substantial batch of SNPs was found by the Collaborative Oncologic Gene-environment Study (COGS) in 2013, coordinated by BCAC, which was subsequently confirmed and extended by combining with other GWAS data [55]. Another 65 loci were detected after the introduction of the OncoArray, a SNP array with a much denser SNP coverage than COGS [10•]. Some of the associated SNPs are more strongly associated with Estrogen Receptor (ER)-negative or ER-positive subtypes of breast cancer $[10 \bullet, 56 \bullet$. The currently known SNPs explain $18 \%$ of the familial relative risk for breast cancer, but a much greater proportion $(\sim 40 \%)$ can be explained when variants that can be reliably imputed from the OncoArray data are included $[10 \bullet, 57 \bullet]$. To validate these latter SNPs, very large case-control studies are needed to reach genome-wide significance levels of association because many of these are expected to be relatively rare $(<5 \%)$ and/or of very small effect sizes.

The breast cancer-associated SNP alleles are distributed normally throughout the general population. This means that, in contrast to pathogenic variants in breast cancer susceptibility genes, all individuals in the population carry a certain number of risk alleles, with most individuals carrying the average number. Individually, these risk alleles confer a very small increase in breast cancer risk but their joint effect may be a substantially higher [8]. In the absence of evidence of clear interactions between SNPs [8, 58], a simple log- 
additive (or multiplicative) model combines all SNPs into a single Polygenic Risk Score (PRS).

Many different PRSs for breast cancer have been published in recent years (Table 1). Most studies have generated PRSs for overall unilateral breast cancer, a few have addressed ER status-specific PRS-models with the use of subtype-specific odds ratios of certain SNPs. Subtype-specific PRSs can potentially be useful to guide clinical management for chemoprevention and other prevention strategies. Two studies [74, 75] have used a PRS to predict contralateral breast cancer, and two have studied the PRS as risk modifier in rare gene mutation carriers (BRCA1, BRCA2, and CHEK2) [72•, 73•]. The number of SNPs, their allele frequencies, and effect sizes determine the discriminatory and predictive power of a PRS. Predictive power of a PRS is usually expressed as odds ratio (OR) per standard deviation unit of the distribution; discriminatory power is assessed by the area under the curve (AUC). The number of SNPs included in a PRS is not strongly correlated with the overall effect size or the AUC. This is because the SNPs detected in the earliest studies, although smaller in number, generally have higher effect sizes than those detected more recently in studies with more statistical power. Including large numbers of SNPs at lower than genome-wide significance thresholds may increase predictive power of the PRS but at the expense of being less specific [57•].

A limitation of many PRSs is that most SNPs contained in it are discovered in European-descent populations and their effects cannot be translated directly to other ethnicities. Studies are ongoing to define breast cancer-associated SNPs and evaluate the European-descent-derived PRSs in Asian and African-American populations.

For all PRS-models, the AUC is modest, but should this alone preclude their application as an individual test to predict if a woman will develop breast cancer or not? A comparison with gene panel testing, which is widely used in the clinic for this purpose, is illustrative. A PRS has been shown to be capable of stratifying women into different risk categories in a clinically meaningful way $[8,62,73 \bullet, 74]$, but the most relevant clinical information of the PRS is in the extreme tails of the distribution. And because these tails concern the general population (as opposed to gene carriers only), the associated attributable risks of the PRS are in fact far greater than that achieved by gene panel testing. For example, the best performing PRS at this moment includes 313 SNPs with an association at a $p$ value threshold three orders below genome-wide significance $\left(P<10^{-5}\right)$. For this PRS, in the general population, $35 \%$ of all breast cancers occur in women in the highest quintile and only $9 \%$ of all breast cancers in the lowest quintile [57•]. Women in the top $1 \%$ of the $\mathrm{PRS}_{313}$ are at fourfold elevated risk relative to population average (95\% CI 3.34 4.89), a risk-level defined in many countries as 'high'. In comparison, BRCA1 mutation carriers explain $<2 \%$ of all breast cancer in Western Caucasian populations [76] and comprise $\sim 0.1 \%$ of the general population. Implementation research is ongoing to introduce the PRS into clinical genetic testing, e.g. in the Netherlands, Germany, the UK and the USA. An example of how individual PRS testing could aid risk counselling in the setting of familial breast cancer is shown in Fig. 1, which highlights how two individuals that would otherwise have received the same risk assessment (sisters in generation IV) on the basis of their identical family history, are clearly classified into distinct risk classes on the basis of their $\mathrm{PRS}_{313}$.

Another potential application of the PRS is in deciding when and how frequent women should undergo breast cancer screening $[6 \bullet, 77]$. In most countries running such screening programs, women are offered screening above a certain age, usually between 45 and 50, when their breast cancer risk exceeds a certain cost-effective level. Women in the lowest quintile of the $\mathrm{PRS}_{313}$ in fact never reach that threshold, whereas those in the highest quintile will attain this level of risk before age 40 years $[57 \bullet]$.

\section{Hormonal, Environmental and Lifestyle Risk Factors}

A number of non-genetic risk factors are presently firmly established as being associated with breast cancer. Besides age, these include physical factors such as body height and weight $[78,79]$. For weight, breast cancer risk is dependent on menopausal status. Weight gain and obesity (BMI > 30) after menopause are associated with an increase in postmenopausal breast cancer [78]. It is likely that higher oestrogen levels underlie this effect in postmenopausal women [80]. A higher mammographic density due to a high proportion of connective and glandular relative to adipose tissue leads to a higher risk for breast cancer [81, 82]. Hormonal factors influencing breast cancer risk include the use of oral contraception and hormone replacement therapy (HRT) [83, 84], as well as age at menarche and menopause [85]. Reproductive history (age of first childbirth or nulliparity) may have similar impact on mammary gland biology $[82,86]$. The lifestyle factors like alcohol use and smoking increase breast cancer risk as well, while physical activity and breastfeeding seem to act protectively [87-89]. Finally, a personal history of benign breast disease also signifies an increased breast cancer risk [82].

\section{Combining Risk Factors}

Since any woman will have only a single certain risk level at a given moment in time to develop breast cancer over the course of her life, genetic and non-genetic risk factors must somehow combine to define that risk. A major challenge for individual breast cancer risk prediction, therefore, is to design risk calculation models that accommodate all known risk factors, which require knowledge about the underlying model and how they 


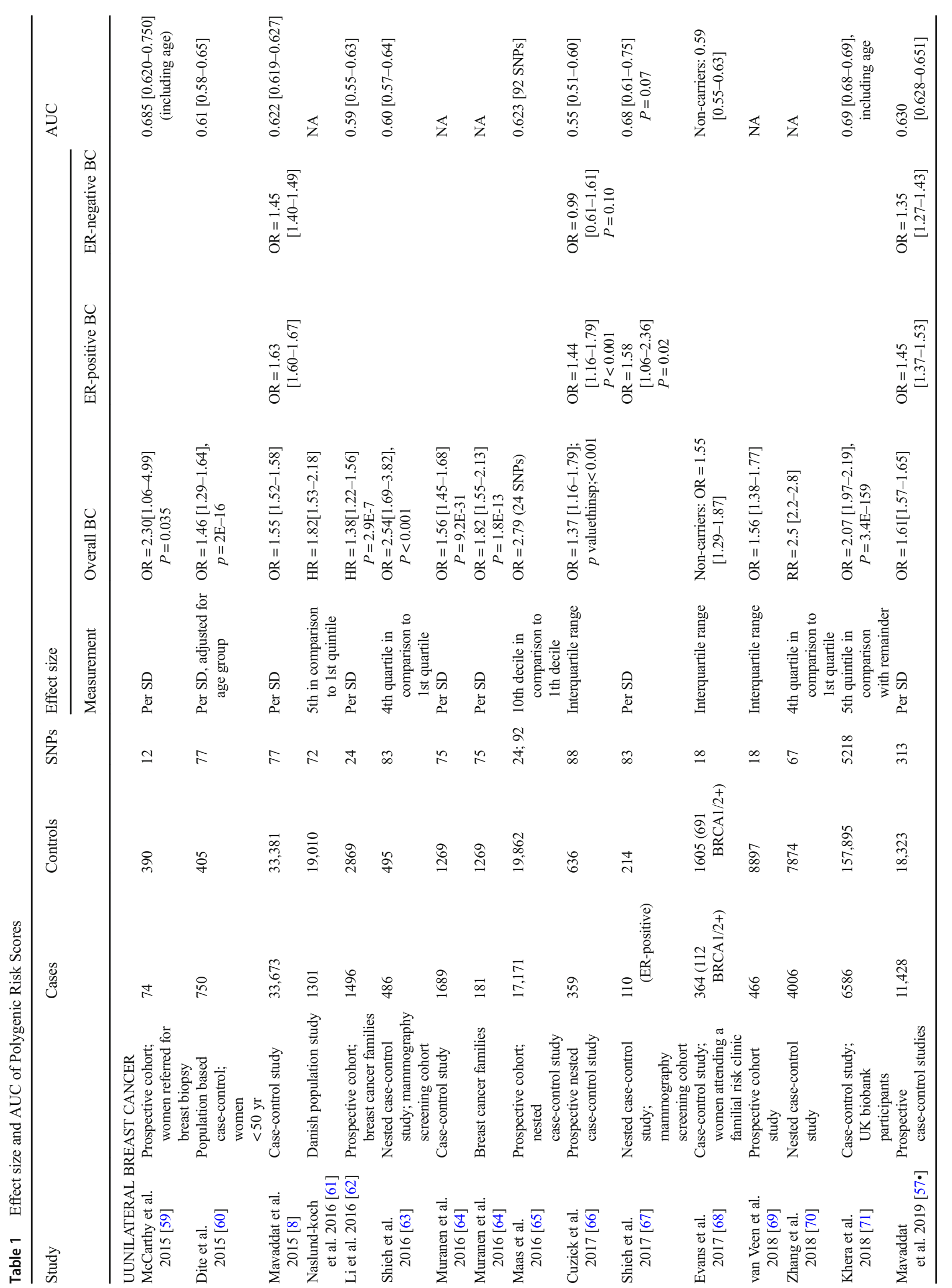




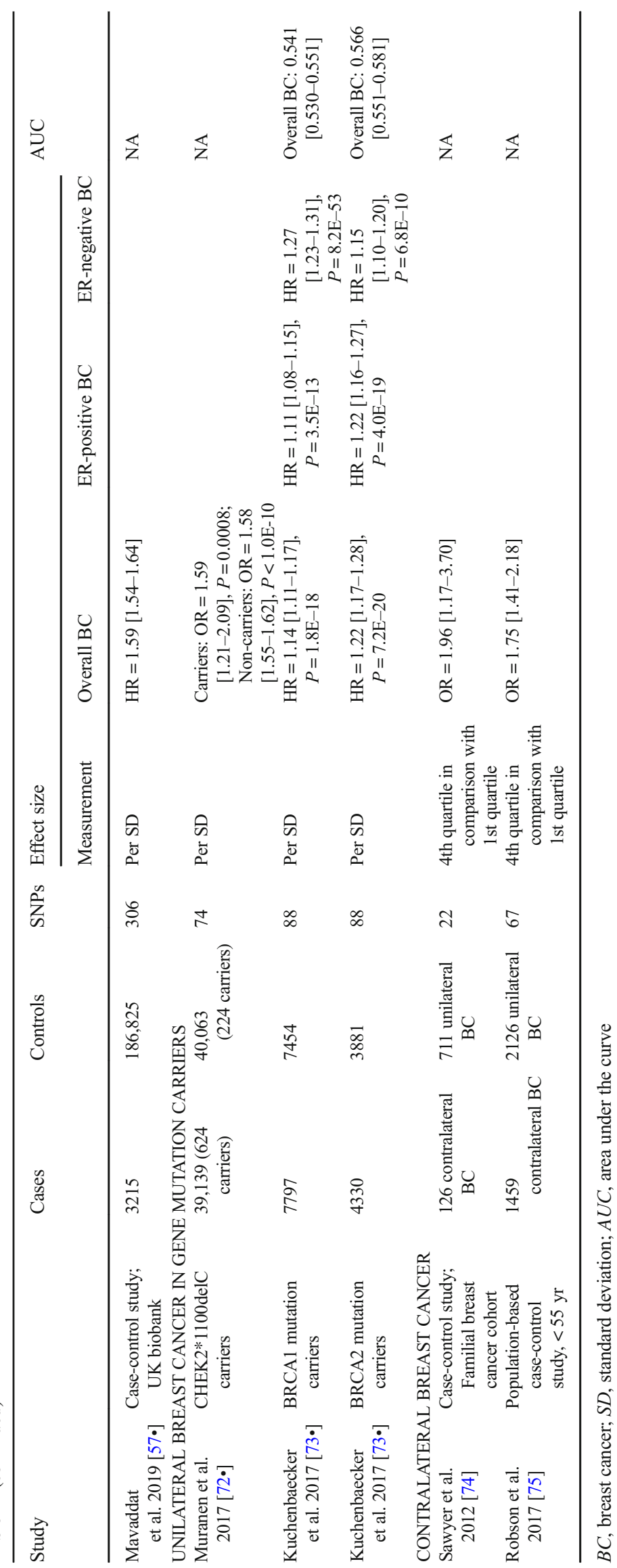


Fig. 1 Standardised Polygenic Risk Scores for breast cancer cases and their female relatives. In this non-BRCA1/2 breast cancer family, multiple family members were genotyped by SNP array. For all genotyped individuals, the $\mathrm{SNP}_{313}$ Polygenic Risk Score (PRS) was calculated. The individual PRSs are standardised to population controls in the BCAC dataset (mean $=0$ and $\mathrm{SD}=1$ in controls). The numbers in the figure are therefore Zscores of the individual PRSs. A higher Z-score indicates a higher breast cancer risk

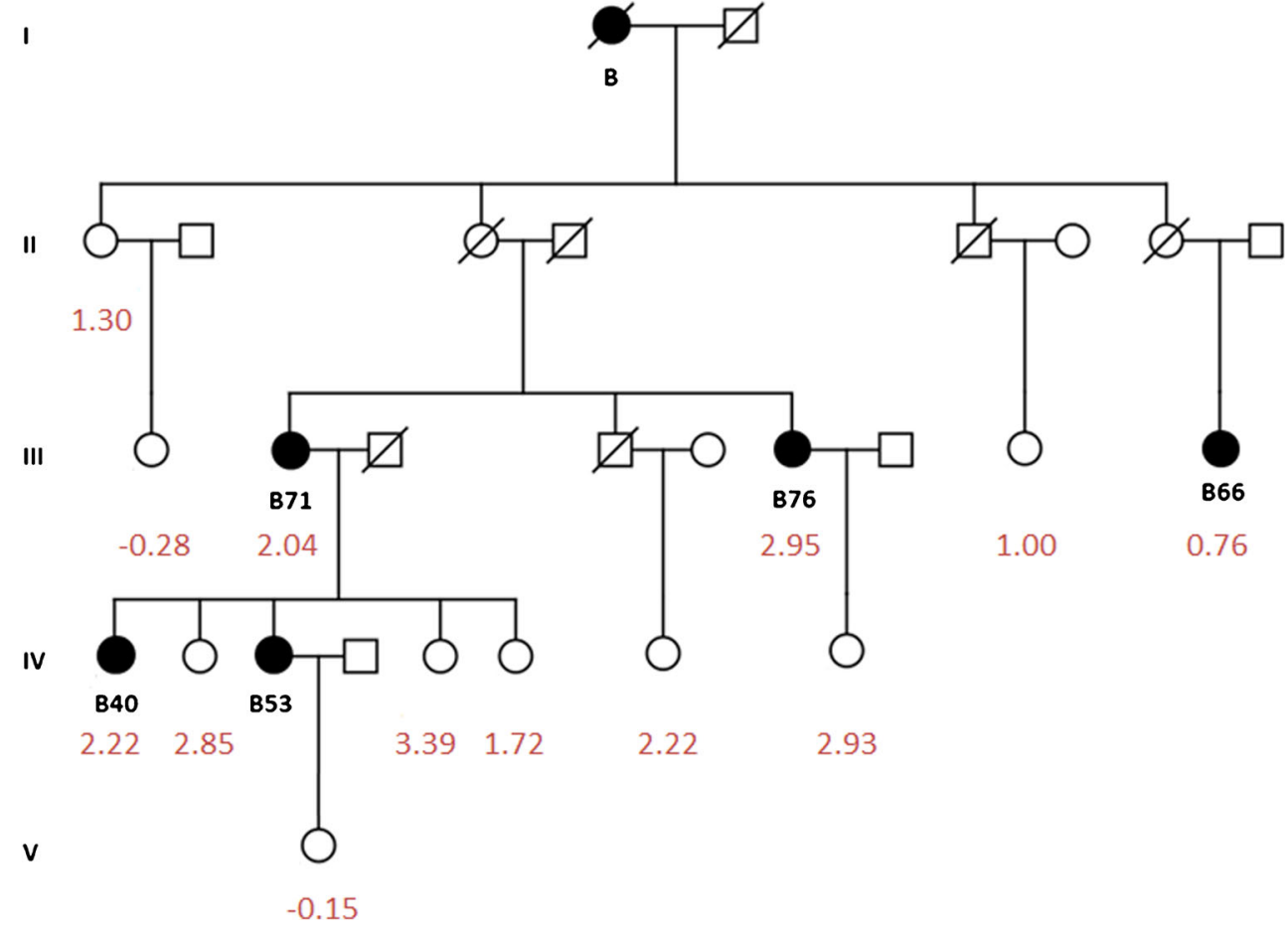

interact. Through the large international consortia such as BCAC, data to design and validate such models are now forthcoming. There are now much more accurate estimates on how the PRS can modify the breast and ovarian cancer risks conferred by pathogenic variants in BRCA1, BRCA2, and CHEK2 [72•, 73-] (Table 1). This can help inform choices and timing of preventive surgery or chemoprevention. The interaction between the 1100 delC variant in CHEK2 and the PRS appears to follow a simple multiplicative interaction, but the per SD hazard ratio estimates in BRCA1 and BRCA2 carriers were smaller than those in general population (Table 1). In BRCA1 carriers, the PRS based on SNPs associated with ER-negative disease showed a much stronger association with breast cancer risk in comparison with the ER-positive PRS, consistent with the predominant ERnegative tumour subtype in BRCA1 carriers [73•]. These issues highlight the complexity of some of these interactions and underscore the necessity of large prospective cohort studies to validate these models. A similar deviation from simple multiplicative interactions has been found for individuals with rare pathogenic variants in more than one breast cancer-associated gene [90]. There is limited evidence for interaction between SNPs and lifestyle/hormonal factors [91]. For environmental factors (e.g. reproductive factors, BMI and alcohol intake), the PRS can, in general, be combined in a multiplicative way [92].

\section{Breast Cancer Risk Prediction Models}

Currently, predicting whether a woman will develop primary breast cancer or not is mainly done within Cancer Family
Clinics. Healthy women who are worried because of their family history for breast cancer can be referred by their general practitioner to such a clinic; alternatively, breast cancer patients with a clear family history are referred by oncologists, also because of the potential impact a gene diagnosis may have for their therapeutic options. The major incentive behind these referrals is the possibility to detect a high-risk variant in $B R C A 1, B R C A 2$ and, more recently, $P A L B 2$. As set forth above, however, such variants are found in $<10 \%$ of all referred families. For women from non-BRCA1/2 breast cancer families, breast cancer risk is often based on family history alone, although more than 20 risk prediction algorithms known today [93] include other risk factors as well. Some well-known risk prediction algorithms are the Gail model, BRCAPRO, Tyrer-Cuzick and the breast and Ovarian Analysis of Disease Incidence and Carrier Estimation Algorithm (BOADICEA). Depending on what the model predicts and for which population, the most appropriate model can be used.

The Gail model predicts breast cancer lifetime risks for women older than 35 years and is widely studied and validated. It includes hormonal risk factors, breast biopsies and affected first-degree relatives [93, 94]. The Chen model extends this by incorporating mammographic breast density as well [95]. The BRCAPRO model calculates breast cancer lifetime risks and the risk of contralateral breast cancer. The calculation is based on family history, the prevalence of $B R C A 1$ and $B R C A 2$ pathogenic variants, population incidence rates and pathological markers for breast cancers [96]. The TyrerCuzick model incorporates hereditary (first- and second- 
degree relatives with breast or ovarian cancer), hormonal and environmental risk factors (age, BMI, menarche, reproductive factors, menopause and HRT) and pathological variables (breast biopsies and benign breast pathology). Mammographic density will be incorporated in the model in an upcoming version [93]. BOADICEA calculates breast cancer lifetime risks and contralateral cancer risks for women with a family history of breast cancer [97]. The model includes tumour pathology characteristics, current cancer incidences and pathogenic variants in ATM, BRCA1, BRCA2, $C H E K 2$ and $P A L B 2$. For BOADICEA, family history is not restricted to a number of relatives or a particular degree.

Several studies have shown an improved discriminative power between breast cancer cases and controls by combining the PRS with a breast cancer risk prediction tool $[60,63,66$, 69]. In one study [62], new breast cancer lifetime risks for women from breast cancer families were calculated by adding the PRS to family-based risk prediction. For up to $23 \%$ of the women, screening recommendations, as stipulated by local management guidelines, could alter.

The BOADICEA model has recently been extended to accommodate a broad range of genetic and non-genetic risk factors for breast cancer, adding mammographic density, reproductive factors, age at menarche and menopause, use of hormones, BMI, body height, alcohol use and the $\mathrm{SNP}_{313}$ PRS to the previous version [98•]. This is the first time that so many factors are combined into a single model. Unsurprisingly, the potential for risk stratification was the greatest when all risk factors were used for risk prediction. Of all factors, the PRS had the largest contribution in risk stratification. Without knowledge of the genetic status of a woman for the rare genes, or family history, the lifetime breast cancer risk varied from $2.8 \%$ for the lowest to $30.6 \%$ for the highest percentile of the PRS. The model assumes that the risk factors and the PRS act multiplicatively, consistent with evidence from previous studies but not yet formally demonstrated for $\mathrm{PRS}_{313}$. Similarly, the assumption that the $\mathrm{PRS}_{313}$ combines multiplicatively with the effects of rare truncating variants in the five breast cancer genes will need validation. Finally, the current BOADICEA model uses population breast cancer risks of several countries but the UK risk factor distributions and therefore may require tailoring for application in other populations.

\section{Conclusion}

Approximately half of familial relative risk of breast cancer can be explained by the genes and variants identified over the past three decades. In order to be able to maximally exploit a woman's genomic data for breast cancer risk prediction, we will have to detect the genetic factors underlying the remaining half. To do so, researchers must face the conundrum of genome-wide significance and costs. Restricting to proteincoding regions by whole-exome sequencing, a so-called burden-type association analysis (counting presumable loss-offunction variants in cases and controls), and using a Bonferroni-corrected significance level of $p<2.5 \times 10^{-6}$ will require data on at least 10,000 cases and 10,000 controls to be sufficiently powered. For whole-genome sequencing, not only the costs per sample are several-fold higher than for exome sequencing, genome-wide significance is at least 50-fold more stringent, requiring many more samples to be analysed. In addition, functional annotation of intronic and intergenic variants, to guide which variants to include in the association analysis, is still in its infancy.

Epidemiology has firmly established and quantified the role of many non-genetic factors in causing breast cancer. Currently, computational models are being built that integrate available knowledge so as to allow highly personal risk estimates. Ultimately, such models will empower women to exploit these risk estimates and take appropriate actions to lower this risk (many risk factors are modifiable). While there are many challenges still to overcome (particularly the lack of evidence to demonstrate improved clinical or economic outcomes), the use of genomic and personal lifestyle data in breast cancer prediction seems imminent.

\section{Compliance with Ethical Standards}

Conflict of Interest Inge M.M. Lakeman, Marjanka K. Schmidt, Christi J. van Asperen and Peter Devilee each declare no potential conflicts of interest.

Human and Animal Rights All reported studies/experiments with human or animal subjects performed by the authors have been previously published and complied with all applicable ethical standards (including the Helsinki declaration and its amendments, institutional/national research committee standards, and international/national/institutional guidelines).

Open Access This article is distributed under the terms of the Creative Commons Attribution 4.0 International License (http:// creativecommons.org/licenses/by/4.0/), which permits unrestricted use, distribution, and reproduction in any medium, provided you give appropriate credit to the original author(s) and the source, provide a link to the Creative Commons license, and indicate if changes were made.

\section{References}

Papers of particular interest, published recently, have been highlighted as:

- Of importance

1. Ferlay J, Colombet M, Soerjomataram I, Dyba T, Randi G, Bettio $\mathrm{M}$, et al. Cancer incidence and mortality patterns in Europe: estimates for 40 countries and 25 major cancers in 2018. Eur J Cancer 
(Oxford, England : 1990). 2018;103:356-87. https://doi.org/10. 1016/j.ejca.2018.07.005.

2. Li X, You R, Wang X, Liu C, Xu Z, Zhou J, et al. Effectiveness of prophylactic surgeries in BRCA1 or BRCA2 mutation carriers: a metaanalysis and systematic review. Clin Cancer Res. 2016;22(15):397181. https://doi.org/10.1158/1078-0432.Ccr-15-1465.

3. Bleyer A. Screening mammography: update and review of publications since our report in the New England Journal of Medicine on the magnitude of the problem in the United States. Acad Radiol. 2015;22(8):949-60. https://doi.org/10.1016/j.acra.2015.03.003.

4. Myers ER, Moorman P, Gierisch JM, Havrilesky LJ, Grimm LJ, Ghate S, et al. Benefits and harms of breast cancer screening: a systematic review. JAMA. 2015;314(15):1615-34. https://doi.org/ 10.1001/jama.2015.13183.

5. Burton H, Chowdhury S, Dent T, Hall A, Pashayan N, Pharoah P. Public health implications from COGS and potential for risk stratification and screening. Nat Genet. 2013;45(4):349-51. https://doi. org/10.1038/ng.2582.

6. Pashayan N, Morris S, Gilbert FJ, Pharoah PDP. Cost-effectiveness and benefit-to-harm ratio of risk-stratified screening for breast cancer: a life-table model. JAMA Oncol. 2018;4(11):1504-10. https:// doi.org/10.1001/jamaoncol.2018.1901 This study describes how risk-based, as opposed to age-based breast cancer screening programs could improve cost-effectiveness, reduce overdiagnosis, and maintain the benefits of screening.

7. Familial breast cancer: collaborative reanalysis of individual data from 52 epidemiological studies including 58,209 women with breast cancer and 101,986 women without the disease. Lancet (London, England). 2001;358(9291):1389-99. https://doi.org/10. 1016/s0140-6736(01)06524-2.

8. Mavaddat N, Pharoah PD, Michailidou K, Tyrer J, Brook MN, Bolla MK, et al. Prediction of breast cancer risk based on profiling with common genetic variants. J Natl Cancer Inst. 2015;107(5). https://doi.org/10.1093/jnci/djv036

9. Michailidou K, Hall P, Gonzalez-Neira A, Ghoussaini M, Dennis J, Milne RL, et al. Large-scale genotyping identifies 41 new loci associated with breast cancer risk. Nat Genet. 2013;45(4):353-61.

10. Michailidou K, Lindstrom S, Dennis J, Beesley J, Hui S, Kar S, et al. Association analysis identifies 65 new breast cancer risk loci. Nature. 2017;551(7678):92-+. https://doi.org/10.1038/ nature 24284 The last in a series of GWA studies, which ultimately formed the basis of the most discriminatory breast cancer PRS currently available

11. Lilyquist J, Ruddy KJ, Vachon CM, Couch FJ. Common genetic variation and breast cancer risk - past, present, and future. Cancer epidemiology, biomarkers \& prevention : a publication of the American Association for Cancer Research, cosponsored by the American Society of Preventive Oncology. 2018. https://doi.org/ 10.1158/1055-9965.epi-17-1144.

12. Miki Y, Swensen J, Shattuck-Eidens D, Futreal PA, Harshman K, Tavtigian S, et al. A strong candidate for the breast and ovarian cancer susceptibility gene BRCA1. Science (New York, NY). 1994;266(5182):66-71.

13. Wooster R, Bignell G, Lancaster J, Swift S, Seal S, Mangion J, et al. Identification of the breast cancer susceptibility gene BRCA2. Nature. 1995;378(6559):789-92. https://doi.org/10.1038/ $378789 \mathrm{a} 0$.

14. Antoniou A, Pharoah PD, Narod S, Risch HA, Eyfjord JE, Hopper $\mathrm{JL}$, et al. Average risks of breast and ovarian cancer associated with BRCA1 or BRCA2 mutations detected in case series unselected for family history: a combined analysis of 22 studies. Am J Hum Genet. 2003;72(5):1117-30. https://doi.org/10.1086/375033.

15. Chen S, Parmigiani G. Meta-analysis of BRCA1 and BRCA2 penetrance. J Clin Oncol. 2007;25(11):1329-33. https://doi.org/10. 1200/jco.2006.09.1066.
16. Nelen MR, Padberg GW, Peeters EA, Lin AY, van den Helm B, Frants RR, et al. Localization of the gene for Cowden disease to chromosome 10q22-23. Nat Genet. 1996;13(1):114-6. https://doi. org/10.1038/ng0596-114.

17. Hearle N, Schumacher V, Menko FH, Olschwang S, Boardman LA, Gille JJ, et al. Frequency and spectrum of cancers in the PeutzJeghers syndrome. Clin Cancer Res. 2006;12(10):3209-15. https://doi.org/10.1158/1078-0432.Ccr-06-0083.

18. Pharoah PD, Guilford P, Caldas C. Incidence of gastric cancer and breast cancer in CDH1 (E-cadherin) mutation carriers from hereditary diffuse gastric cancer families. Gastroenterology. 2001;121(6): 1348-53.

19. Madanikia SA, Bergner A, Ye X, Blakeley JO. Increased risk of breast cancer in women with NF1. Am J Med Genet A. 2012;158a(12):3056-60. https://doi.org/10.1002/ajmg.a.35550.

20. Malkin D, Li FP, Strong LC, Fraumeni JF Jr, Nelson CE, Kim DH, et al. Germ line p53 mutations in a familial syndrome of breast cancer, sarcomas, and other neoplasms. Science (New York, NY). 1990;250(4985):1233-8.

21. Renwick A, Thompson D, Seal S, Kelly P, Chagtai T, Ahmed M, et al. ATM mutations that cause ataxia-telangiectasia are breast cancer susceptibility alleles. Nat Genet. 2006;38(8):873-5. https:// doi.org/10.1038/ng1837.

22. D' Andrea AD, Grompe M. The Fanconi anaemia/BRCA pathway. Nat Rev Cancer. 2003;3(1):23-34.

23. Meijers-Heijboer H, van den Ouweland A, Klijn J, Wasielewski M, de Snoo A, Oldenburg R, et al. Low-penetrance susceptibility to breast cancer due to $\mathrm{CHEK} 2(*) 1100 \mathrm{delC}$ in noncarriers of BRCA1 or BRCA2 mutations. Nat Genet. 2002;31(1):55-9. https://doi.org/ 10.1038/ng879.

24. Rahman N, Seal S, Thompson D, Kelly P, Renwick A, Elliott A, et al. PALB2, which encodes a BRCA2-interacting protein, is a breast cancer susceptibility gene. Nat Genet. 2007;39(2):165-7. https://doi.org/10.1038/ng1959.

25. Bogdanova N, Feshchenko S, Schurmann P, Waltes R, Wieland B, Hillemanns $\mathrm{P}$, et al. Nijmegen breakage syndrome mutations and risk of breast cancer. Int J Cancer. 2008;122(4):802-6. https://doi. org/10.1002/ijc.23168.

26. Easton DF, Pharoah PD, Antoniou AC, Tischkowitz M, Tavtigian $\mathrm{SV}$, Nathanson KL, et al. Gene-panel sequencing and the prediction of breast-cancer risk. N Engl J Med. 2015;372(23):2243-57. https://doi.org/10.1056/NEJMsr1501341.

27. Wendt $\mathrm{C}$, Margolin S. Identifying breast cancer susceptibility genes - a review of the genetic background in familial breast cancer. Acta Oncol. 2019;58:1-12. https://doi.org/10.1080/0284186x.2018. 1529428.

28. Antoniou AC, Casadei S, Heikkinen T, Barrowdale D, Pylkas K, Roberts J, et al. Breast-cancer risk in families with mutations in PALB2. N Engl J Med. 2014;371(6):497-506.

29. Couch FJ, Shimelis H, Hu CL, Hart SN, Polley EC, Na J, et al. Associations between cancer predisposition testing panel genes and breast cancer. JAMA Oncol. 2017;3(9):1190-6. https://doi.org/10. $1001 /$ jamaoncol.2017.0424 One of the first studies to attempt to replicate the many putative breast cancer genes by association in a large-scale case-control design.

30. Lu HM, Li S, Black MH, Lee S, Hoiness R, Wu S, et al. Association of breast and ovarian cancers with predisposition genes identified by large-scale sequencing. JAMA Oncol. 2018;5(1):51-7. https:// doi.org/10.1001/jamaoncol.2018.2956.

31. Graffeo R, Livraghi L, Pagani O, Goldhirsch A, Partridge AH, Garber JE. Time to incorporate germline multigene panel testing into breast and ovarian cancer patient care. Breast Cancer Res Treat. 2016;160(3):393-410. https://doi.org/10.1007/s10549-016-4003-9.

32. Richards S, Aziz N, Bale S, Bick D, Das S, Gastier-Foster J, et al. Standards and guidelines for the interpretation of sequence variants: a joint consensus recommendation of the American College of 
Medical Genetics and Genomics and the Association for Molecular Pathology. Genet Med. 2015;17(5):405-24. https://doi.org/10. 1038/gim.2015.30.

33. Rebbeck TR, Mitra N, Domchek SM, Wan F, Friebel TM, Tran TV, et al. Modification of BRCA1-associated breast and ovarian cancer risk by BRCA1-interacting genes. Cancer Res. 2011;71(17):5792-805.

34. Shimelis H, Mesman RLS, Von Nicolai C, Ehlen A, Guidugli L, Martin C, et al. BRCA2 hypomorphic missense variants confer moderate risks of breast cancer. Cancer Res. 2017;77(11):278999. https://doi.org/10.1158/0008-5472.can-16-2568 In vitro testing of BRCA2 functionality can help to identify variants conferring moderate breast cancer risks.

35. Moghadasi S, Meeks HD, Vreeswijk MP, Janssen LA, Borg A, Ehrencrona H, et al. The BRCA1 c. 5096G>A p.Arg1699Gln (R1699Q) intermediate risk variant: breast and ovarian cancer risk estimation and recommendations for clinical management from the ENIGMA consortium. J Med Genet. 2018;55(1):15-20. https://doi. org/10.1136/jmedgenet-2017-104560.

36. Southey MC, Goldgar DE, Winqvist R, Pylkas K, Couch F, Tischkowitz M, et al. PALB2, CHEK2 and ATM rare variants and cancer risk: data from COGS. J Med Genet. 2016;53(12): 800-11. https://doi.org/10.1136/jmedgenet-2016-103839.

37. Bernstein JL, Teraoka S, Southey MC, Jenkins MA, Andrulis IL, Knight JA, et al. Population-based estimates of breast cancer risks associated with ATM gene variants c.7271T $>\mathrm{G}$ and c.1066-6T>G (IVS10-6T $>$ G) from the breast cancer family registry. Hum Mutat. 2006;27(11):1122-8.

38. Thompson ER, Gorringe KL, Rowley SM, Li N, McInerny S, Wong-Brown MW, et al. Reevaluation of the BRCA2 truncating allele c.9976A > T (p.Lys3326Ter) in a familial breast cancer context. Sci Rep. 2015;5:14800.

39. Toland AE, Andreassen PR. DNA repair-related functional assays for the classification of BRCA1 and BRCA2 variants: a critical review and needs assessment. J Med Genet. 2017;54(11):721-31. https://doi.org/10.1136/jmedgenet-2017-104707.

40. Chompret A, Brugieres L, Ronsin M, Gardes M, Dessarps-Freichey F, Abel A, et al. P53 germline mutations in childhood cancers and cancer risk for carrier individuals. Br J Cancer. 2000;82(12):19327. https://doi.org/10.1054/bjoc.2000.1167.

41. O'Shea R, Clarke R, Berkley E, Giffney C, Farrell M, O'Donovan $\mathrm{E}$, et al. Next generation sequencing is informing phenotype: a TP53 example. Familial Cancer. 2018;17(1):123-8. https://doi. org/10.1007/s10689-017-0002-1.

42. Rana HQ, Gelman R, LaDuca H, McFarland R, Dalton E, Thompson J, et al. Differences in TP53 mutation carrier phenotypes emerge from panel-based testing. J Natl Cancer Inst. 2018;110(8): 863-70. https://doi.org/10.1093/jnci/djy001.

43. de Andrade KC, Frone MN, Wegman-Ostrosky T, Khincha PP, Kim J, Amadou A, et al. Variable population prevalence estimates of germline TP53 variants: a gnomAD-based analysis. Hum Mutat. 2019;40(1):97-105. https://doi.org/10.1002/humu.23673.

44. Consortium TCBCC-C. CHEK2*1100delC and susceptibility to breast cancer: a collaborative analysis involving 10,860 breast cancer cases and 9,065 controls from ten studies. Am J Hum Genet. 2004;74(6):1175-82.

45. Schmidt MK, Hogervorst F, van Hien R, Cornelissen S, Broeks A, Adank MA, et al. Age- and tumor subtype-specific breast cancer risk estimates for CHEK $2 * 1100$ delC carriers. J Clin Oncol. 2016;34(23):2750-60. https://doi.org/10.1200/jco.2016.66.5844.

46. Tung N, Battelli C, Allen B, Kaldate R, Bhatnagar S, Bowles K, et al. Frequency of mutations in individuals with breast cancer referred for BRCA1 and BRCA2 testing using next-generation sequencing with a 25-gene panel. Cancer. 2015;121(1):25-33. https:// doi.org/10.1002/cncr.29010.

47. Desmond A, Kurian AW, Gabree M, Mills MA, Anderson MJ, Kobayashi Y, et al. Clinical actionability of multigene panel testing for hereditary breast and ovarian cancer risk assessment. JAMA Oncol. 2015;1(7):943-51. https://doi.org/10.1001/jamaoncol. 2015.2690.

48. Lerner-Ellis J, Khalouei S, Sopik V, Narod SA. Genetic risk assessment and prevention: the role of genetic testing panels in breast cancer. Expert Rev Anticancer Ther. 2015;15(11):1315-26. https://doi.org/10.1586/14737140.2015.1090879.

49. Kapoor NS, Curcio LD, Blakemore CA, Bremner AK, McFarland RE, West JG, et al. Multigene panel testing detects equal rates of pathogenic BRCA1/2 mutations and has a higher diagnostic yield compared to limited BRCA $1 / 2$ analysis alone in patients at risk for hereditary breast cancer. Ann Surg Oncol. 2015;22(10):3282-8. https://doi.org/10.1245/s10434-015-4754-2.

50. Thompson ER, Rowley SM, Li N, McInerny S, Devereux L, WongBrown MW, et al. Panel testing for familial breast cancer: calibrating the tension between research and clinical care. J Clin Oncol. 2016. https://doi.org/10.1200/JCO.2015.63.7454.

51. Susswein LR, Marshall ML, Nusbaum R, Vogel Postula KJ, Weissman SM, Yackowski L, et al. Pathogenic and likely pathogenic variant prevalence among the first 10,000 patients referred for next-generation cancer panel testing. Genet Med. 2015. https://doi. org/10.1038/gim.2015.166.

52. Kuchenbaecker KB, Hopper JL, Barnes DR, Phillips KA, Mooij $\mathrm{TM}$, Roos-Blom MJ, et al. Risks of breast, ovarian, and contralateral breast cancer for BRCA1 and BRCA2 mutation carriers. JAMA. 2017;317(23):2402-16. https://doi.org/10.1001/jama. 2017.7112.

53. Rebbeck TR, Friebel TM, Friedman E, Hamann U, Huo D, Kwong A, et al. Mutational spectrum in a worldwide study of 29,700 families with BRCA1 or BRCA2 mutations. Hum Mutat. 2018;39(5): 593-620. https://doi.org/10.1002/humu.23406.

54. Turnbull C, Sud A, Houlston RS. Cancer genetics, precision prevention and a call to action. Nat Genet. 2018;50(9):1212-8. https:// doi.org/10.1038/s41588-018-0202-0.

55. Michailidou K, Beesley J, Lindstrom S, Canisius S, Dennis J, Lush MJ, et al. Genome-wide association analysis of more than 120,000 individuals identifies 15 new susceptibility loci for breast cancer. Nat Genet. 2015;47(4):373-80. https://doi.org/10.1038/ng.3242.

56. Milne RL, Kuchenbaecker KB, Michailidou K, Beesley J, Kar S, Lindstrom $\mathrm{S}$, et al. Identification of ten variants associated with risk of estrogen-receptor-negative breast cancer. Nat Genet. 2017;49(12):1767-78. https://doi.org/10.1038/ng.3785 Definitive evidence that some SNPs predispose specifically to ERnegative breast cancer subtypes.

57. Mavaddat N, Michailidou K, Dennis J, Lush M, Fachal L, Lee A, et al. Polygenic risk scores for prediction of breast cancer and breast cancer subtypes. Am J Hum Genet. 2019;104(1):21-34. https://doi. org/10.1016/j.ajhg.2018.11.002 Presentation of the most predictive breast cancer PRS available to date, consisting of 313 SNPs.

58. Milne RL, Herranz J, Michailidou K, Dennis J, Tyrer JP, Zamora MP, et al. A large-scale assessment of two-way SNP interactions in breast cancer susceptibility using 46450 cases and 42461 controls from the breast cancer association consortium. Hum Mol Genet. 2014;23(7):1934-46.

59. McCarthy AM, Keller B, Kontos D, Boghossian L, McGuire E, Bristol M, et al. The use of the Gail model, body mass index and SNPs to predict breast cancer among women with abnormal (BIRADS 4) mammograms. Breast Cancer Res. 2015;17:1. https://doi. org/10.1186/s13058-014-0509-4.

60. Dite GS, MacInnis RJ, Bickerstaffe A, Dowty JG, Allman R, Apicella $\mathrm{C}$ et al. Breast cancer risk prediction using clinical models and 77 independent risk-associated SNPs for women aged under 50 years: Australian Breast Cancer Family Registry. Cancer Epidemiol Biomarkers Prev. 2015;1055-9965. https://doi.org/10.1158/10559965.EPI-15-0838. 
61. Naslund-Koch C, Nordestgaard BG, Bojesen SE. Common breast cancer risk alleles and risk assessment: a study on 35,441 individuals from the Danish general population. Ann Oncol. 2016. https:// doi.org/10.1093/annonc/mdw536.

62. Li H, Feng B, Miron A, Chen X, Beesley J, Bimeh E, et al. Breast cancer risk prediction using a polygenic risk score in the familial setting: a prospective study from the breast cancer family registry and kConFab. Genet Med. 2016;19:30-5. https://doi.org/10.1038/ gim.2016.43.

63. Shieh Y, Hu D, Ma L, Huntsman S, Gard CC, Leung JW, et al. Breast cancer risk prediction using a clinical risk model and polygenic risk score. Breast Cancer Res Treat. 2016;159(3):513-25. https://doi.org/10.1007/s10549-016-3953-2.

64. Muranen TA, Mavaddat N, Khan S, Fagerholm R, Pelttari L, Lee A, et al. Polygenic risk score is associated with increased disease risk in 52 Finnish breast cancer families. Breast Cancer Res Treat. 2016;158(3):463-9. https://doi.org/10.1007/s10549-016-3897-6.

65. Maas P, Barrdahl M, Joshi AD, Auer PL, Gaudet MM, Milne RL, et al. Breast cancer risk from modifiable and nonmodifiable risk factors among White women in the United States. JAMA Oncol. 2016;2(10):1295-302. https://doi.org/10.1001/jamaoncol.2016. 1025.

66. Cuzick J, Brentnall AR, Segal C, Byers H, Reuter C, Detre S, et al. Impact of a panel of 88 single nucleotide polymorphisms on the risk of breast cancer in high-risk women: results from two randomized tamoxifen prevention trials. J Clin Oncol. 2017;35(7):743-50. https://doi.org/10.1200/jco.2016.69.8944.

67. Shieh Y, Hu D, Ma L, Huntsman S, Gard CC, Leung JWT, et al. Joint relative risks for estrogen receptor-positive breast cancer from a clinical model, polygenic risk score, and sex hormones. Breast Cancer Res Treat. 2017;166(2):603-12. https://doi.org/10.1007/ s10549-017-4430-2.

68. Evans DG, Brentnall A, Byers H, Harkness E, Stavrinos P, Howell A, et al. The impact of a panel of 18 SNPs on breast cancer risk in women attending a UK familial screening clinic: a case-control study. J Med Genet. 2017;54(2):111-3. https://doi.org/10.1136/ jmedgenet-2016-104125.

69. van Veen EM, Brentnall AR, Byers H, Harkness EF, Astley SM, Sampson S, et al. Use of single-nucleotide polymorphisms and mammographic density plus classic risk factors for breast cancer risk prediction. JAMA Oncol. 2018;4(4):476-82. https://doi.org/ 10.1001/jamaoncol.2017.4881.

70. Zhang X, Rice M, Tworoger SS, Rosner BA, Eliassen AH, Tamimi RM, et al. Addition of a polygenic risk score, mammographic density, and endogenous hormones to existing breast cancer risk prediction models: a nested case-control study. PLoS Med. 2018;15(9): e1002644. https://doi.org/10.1371/journal.pmed.1002644.

71. Khera AV, Chaffin M, Aragam KG, Haas ME, Roselli C, Choi SH, et al. Genome-wide polygenic scores for common diseases identify individuals with risk equivalent to monogenic mutations. Nat Genet. 2018;50(9):1219-24. https://doi.org/10.1038/s41588-0180183-z.

72. Muranen TA, Greco D, Blomqvist C, Aittomaki K, Khan S, Hogervorst F, et al. Genetic modifiers of CHEK2*1100delC-associated breast cancer risk. Genet Med. 2017;19(5):599-603. https:// doi.org/10.1038/gim.2016.147 A Major loss-of-function variant in CHEK2 acts multiplicatively with the PRS to increase breast cancer risk.

73. Kuchenbaecker KB, McGuffog L, Barrowdale D, Lee A, Soucy P, Dennis J, et al. Evaluation of polygenic risk scores for breast and ovarian cancer risk prediction in BRCA1 and BRCA2 mutation carriers. J Natl Cancer Inst. 2017;109(7). https://doi.org/10.1093/ jnci/djw302. Detailed description of how the PRS modifies breast and ovarian cancer risks conferred by BRCA1 and BRCA2.
74. Sawyer S, Mitchell G, McKinley J, Chenevix-Trench G, Beesley J, Chen XQ, et al. A role for common genomic variants in the assessment of familial breast cancer. JClinOncol. 2012;30(35):4330-6. https://doi.org/10.1200/JCO.2012.41.7469.

75. Robson ME, Reiner AS, Brooks JD, Concannon PJ, John EM, Mellemkjaer L, et al. Association of common genetic variants with contralateral breast cancer risk in the WECARE study. J Natl Cancer Inst. 2017;109(10). https://doi.org/10.1093/jnci/djx051.

76. Ford D, Easton D, Peto J. Estimates of the gene frequency of BRCA1 and its contribution to breast and ovarian cancer incidence. Am J Hum Genet. 1995;57:1457-62.

77. Pharoah PD, Antoniou AC, Easton DF, Ponder BA. Polygenes, risk prediction, and targeted prevention of breast cancer. N Engl J Med. 2008;358(26):2796-803.

78. Lahmann PH, Hoffmann K, Allen N, van Gils CH, Khaw KT, Tehard B, et al. Body size and breast cancer risk: findings from the European prospective investigation into cancer and nutrition (EPIC). Int J Cancer. 2004;111(5):762-71. https://doi.org/10. 1002/ijc.20315.

79. Green J, Cairns BJ, Casabonne D, Wright FL, Reeves G, Beral V. Height and cancer incidence in the million women study: prospective cohort, and meta-analysis of prospective studies of height and total cancer risk. Lancet Oncol. 2011;12(8):785-94. https://doi.org/ 10.1016/s1470-2045(11)70154-1.

80. Key TJ, Appleby PN, Reeves GK, Roddam A, Dorgan JF, Longcope C, et al. Body mass index, serum sex hormones, and breast cancer risk in postmenopausal women. J Natl Cancer Inst. 2003;95(16):1218-26.

81. McCormack VA, dos Santos Silva I. Breast density and parenchymal patterns as markers of breast cancer risk: a meta-analysis. Cancer Epidemiol Biomarkers Prev. 2006;15(6):1159-69. https:// doi.org/10.1158/1055-9965.Epi-06-0034.

82. Nelson HD, Zakher B, Cantor A, Fu R, Griffin J, O'Meara ES, et al. Risk factors for breast cancer for women aged 40 to 49 years: a systematic review and meta-analysis. Ann Intern Med. 2012;156(9):635-48. https://doi.org/10.7326/0003-4819-156-9201205010-00006.

83. Beral V, Reeves G, Bull D, Green J. Breast cancer risk in relation to the interval between menopause and starting hormone therapy. $\mathrm{J}$ Natl Cancer Inst. 2011;103(4):296-305. https://doi.org/10.1093/ jnci/djq527.

84. Hunter DJ, Colditz GA, Hankinson SE, Malspeis S, Spiegelman D, Chen W, et al. Oral contraceptive use and breast cancer: a prospective study of young women. Cancer Epidemiol Biomarkers Prev. 2010;19(10):2496-502. https://doi.org/10.1158/1055-9965.Epi-100747.

85. Cancer CGoHFiB. Menarche, menopause, and breast cancer risk: individual participant meta-analysis, including 118964 women with breast cancer from 117 epidemiological studies. Lancet Oncol. 2012;13(11):1141-51. https://doi.org/10.1016/s14702045(12)70425-4.

86. Breast cancer and breastfeeding: collaborative reanalysis of individual data from 47 epidemiological studies in 30 countries, including 50302 women with breast cancer and 96973 women without the disease. Lancet (London, England). 2002;360(9328):187-95. https://doi.org/10.1016/s0140-6736(02)09454-0.

87. Hamajima N, Hirose K, Tajima K, Rohan T, Calle EE, Heath CW $\mathrm{Jr}$, et al. Alcohol, tobacco and breast cancer-collaborative reanalysis of individual data from 53 epidemiological studies, including 58 , 515 women with breast cancer and 95,067 women without the disease. Br J Cancer. 2002;87(11):1234-45. https://doi.org/10. 1038/sj.bjc.6600596.

88. Gram IT, Park SY, Kolonel LN, Maskarinec G, Wilkens LR, Henderson BE, et al. Smoking and risk of breast cancer in a racially/ethnically diverse population of mainly women who do 
not drink alcohol: the MEC study. Am J Epidemiol. 2015;182(11): 917-25. https://doi.org/10.1093/aje/kwv092.

89. Pizot C, Boniol M, Mullie P, Koechlin A, Boniol M, Boyle P, et al. Physical activity, hormone replacement therapy and breast cancer risk: a meta-analysis of prospective studies. Eur J Cancer. 2016;52: 138-54. https://doi.org/10.1016/j.ejca.2015.10.063.

90. Turnbull C, Seal S, Renwick A, Warren-Perry M, Hughes D, Elliott A, et al. Gene-gene interactions in breast cancer susceptibility. Hum Mol Genet. 2012;21(4):958-62. https://doi.org/10.1093/hmg/ ddr525.

91. Rudolph A, Chang-Claude J, Schmidt MK. Gene-environment interaction and risk of breast cancer. Br J Cancer. 2016;114(2):12533. https://doi.org/10.1038/bjc.2015.439.

92. Rudolph A, Song M, Brook MN, Milne RL, Mavaddat N, Michailidou K, et al. Joint associations of a polygenic risk score and environmental risk factors for breast cancer in the breast cancer association consortium. Int J Epidemiol. 2018;47:526-36. https:// doi.org/10.1093/ije/dyx242.

93. Cintolo-Gonzalez JA, Braun D, Blackford AL, Mazzola E, Acar A, Plichta JK, et al. Breast cancer risk models: a comprehensive overview of existing models, validation, and clinical applications. Breast Cancer Res Treat. 2017;164(2):263-84. https://doi.org/10. 1007/s10549-017-4247-z.

94. Gail MH, Brinton LA, Byar DP, Corle DK, Green SB, Schairer C, et al. Projecting individualized probabilities of developing breast cancer for white females who are being examined annually. J Natl Cancer Inst. 1989;81(24):1879-86.

95. Chen J, Pee D, Ayyagari R, Graubard B, Schairer C, Byrne C, et al. Projecting absolute invasive breast cancer risk in white women with a model that includes mammographic density. J Natl Cancer Inst. 2006;98(17):1215-26. https://doi.org/10.1093/jnci/djj332.

96. Mazzola E, Blackford A, Parmigiani G, Biswas S. Recent enhancements to the genetic risk prediction model BRCAPRO. Cancer Informat. 2015;14(Suppl 2):147-57. https://doi.org/10.4137/cin. S17292.

97. Lee AJ, Cunningham AP, Kuchenbaecker KB, Mavaddat N, Easton DF, Antoniou AC. BOADICEA breast cancer risk prediction model: updates to cancer incidences, tumour pathology and web interface. Br J Cancer. 2014;110(2):535-45. https://doi.org/10.1038/bjc. 2013.730.

98. Lee A, Mavaddat N, Wilcox AN, Cunningham AP, Carver T, Hartley S, et al. BOADICEA: a comprehensive breast cancer risk prediction model incorporating genetic and nongenetic risk factors. Genet Med. 2019. https://doi.org/10.1038/s41436-018-0406-9 This paper describes the most elaborate breast cancer risk prediction model available to date, including potential clinical applications.

Publisher's Note Springer Nature remains neutral with regard to jurisdictional claims in published maps and institutional affiliations. 